\title{
Science Policy or Social Policy?
}

\author{
Wouter Van Rossum
}

Research and development, or more generally, science and technology have only relatively recently received attention from the policy sector. Only since World War II have governments explicitly developed policies regarding science and technology. In the period after the war (and initially most prominently in the U.S.), war efforts in the field of science and technology were redirected toward more peaceful objectives.

At first, the role was a supporting and rather restricted one: scientific knowledge, particularly basic scientific knowledge, could not be a self-evident task of the economic sector. This is economically understandable, as firms will not invest in basic scientific research when they cannot sufficiently appropriate returns on their investments. Consequently, the financing and organization of basic scientific research primarily became a task for the public sector.

Of course, the boundary between public and private investment in scientific knowledge has never been clear, just as the boundary between basic and applied scientific research remains unclear. In addition, political cultures differ about the extent of public support and interest in the financing basic scientific research. Generally speaking, however, public interest tended to be on the side of scientific research, while private interest was on the applied side of science.

This general perspective on the role of governments in the organization and financing of scientific research was supplemented by a specific view on the extent to which governments should interfere (or, more precisely, should refrain from interfering) in decision making about basic scientific research.

As Spiegel-Rosing has pointed out, the steering model could be defined as a pragmatic one: the public sector should financially support basic scientific research and refrain from steering influences. In contrast, applied scientific research and technology were considered the concern of private industrial firms, and should be steered according to the objectives of these firms.

Wouter Van Rossum is professor of Social and Organizational Aspects of Science and Technology in the School of Management and Organization at Groningen University in the Netherlands. He is currently on sabbatical at the Graduate School of Business, Stanford University.

Knowledge and Policy: The International Journal of Knowledge Transfer and Utilization, Winter 1997, Vol. 9, Number 4, pp. 103-112. 
At that time, science and technology policy was predominantly "science policy." Technology policy was confined to policies concerning specific technologies, such as nuclear technology. This distinction between public and private interest remained more or less intact until the 1960s. In addition, signals about the potential negative effects of technology and the apparent problem the market had in dealing with these signals clearly indicated the need for regulatory measures by government. Two examples of such signals include the concerns of the Club of Rome regarding the limits of economic growth and the recognition of the negative environmental effects of new technologies.

It was felt that technological change should be controlled. This required an assessment of the potential noneconomic (e.g., social, environmental) effects of the implementation of technologies. The establishment of the Office of Technology Assessment by the U.S. Congress in 1972 was a milestone indicating the new interest of government in technological development. Nevertheless, this interest was regulatory and not promotional.

Shortly thereafter, there was a renewed and distinct interest in government to develop policy measures directed towards the promotion of technological development. The distinction between the former and the latter interest was two-fold: other governmental agencies were involved in the latter; and there was a different indirect relationship with other aspects of science policy. This development, which occurred in most western countries (in some earlier than others), was specifically related to the aftermath of the first oil crisis of 1973 and related economic contraction that resulted in most developed countries. Science and technology were perceived as important mechanisms to regain economic growth. More precisely, new scientifically based technologies - such as information technology, biotechnology and new materials, become the focus of attempts by governments to stimulate new economic development.

Whereas the explicit attempt to control and develop new technologies occurred more or less simultaneously, for the most part, the two are not related. Quite often different government agencies were (and are) responsible for the various policies. For example, in The Netherlands, the Ministry of Economic Affairs established policies to develop new medical technologies, while the Ministry of Welfare, Health and Culture simultaneously established policies to control the use of new medical technologies (among which the development of technology assessment).

More recently, new economic growth resulting from the development and implementation of new production and process technologies-especially information technology-requires new types of related science and technology policies. Some research fields have become strategically important for the development of new technologies. Moreover, the pace of technology development has increased so rapidly that the development of new technologies has to be accompanied by organizational innovations: for example, more flexible use of human labor and a shift from production by separate firms to production processes that link various firms in networks. This requires new types of integrated pollicies; unclear is what should be the nature of these policies. 
If we can accept this brief sketch as indicative of the development of science and technology policy in the postwar period, then a number of questions need to be asked: What factors determined the changes in the nature of these policies? Why are so many national experiences comparable in this respect? In fact, the totality of the field indicated by the term "science and technology policy" - or as it is currently expressed "innovation policy," is an amalgam of different policy fields developed at different times and under different circumstances.

The questions previously raised are the more interesting because the role of government, with respect to science and technology, is not completely clear. Nevertheless, economists argue that government should interfere in the development of basic scientific knowledge. They contend that the market will not sustain risk-taking in the development of such knowledge. However, economists are not clear about what should be the nature of government intervention-complicated by the lack of clarity about the boundary between basic and applied or application-oriented research.

Nor is the role of government clear with respect to technology development. Although industrial firms have the major developmental task in this area, even the largest multinationals do not have the funds to development technologies on their own. This is particularly the case with respect to large scale, science-based technologies. This implies that governmental intervention in technology development can and has taken different forms in different countries.

A recent attempt to address the questions raised above is the volume Technology Policy: Towards an Integration of Social and Ecological Concerns, edited by Georg Aichholzer and Gerd Schienstock (Walter de Gruyter, Berlin/New York, 1994). The book comprises a collection of articles that attempt to conceptually and empirically circumscribe the state of affairs in the field of technology policy.

In this rather loosely titled volume, the various authors cover the broad territory of technology policy; socioeconomic innovation policy; socially oriented innovation; innovation policy; constructive technology assessment; high-tech industrial development planning; socially oriented technology policy; national policies devoted to technology and environment; and science and technology policy. Unfortunately, nowhere in the book are concise definitions of the subject matter to be found. Consequently, this volume does not easily allow the reader to make systematic comparisons between the authors' conceptualizations and the experience of these policies at the national level. In fact, the contents of this volume underline the fuzzy nature of boundaries between these technology and innovation policy fields.

The book opens with conceptual articles by Schienstock, Badham, Edquist, Braun, Badham and Naschold, and Simonis. These authors formulate the context and nature of the changes in postwar science and technoloy policies. In the second part of the book, the focus is on changes in research and technoloy policy in nine different countries. ${ }^{1}$

One can agree with the authors of this volume that it is difficult to clearly circumscribe the broad field of science and technology or innovation policy. 
Nevertheless, there are considerable differences in the nature and the actors involved when comparing, for example, research policy, technology policy and industrial policy - or, for that matter, environmental policy. By including all of these fields in the discussion, the authors leave the reader with a lack of clarity about which policy developments are being referenced in their discussion of postwar developments. The lack of an adequate definition also hampers the discussion of the differences between these policies in the various countries.

In general, the argument proffered in the book is sound: that in most developed countries there have been various changes at different periods of time. The authors could have made a valuable contribution if they had been able to indicate the extent to which these various types of policies were similar. This could have been done, for example, by comparing different nations to determine whether changes took place at approximately the same time. The lack of attention to the precise nature of research and technology policies also precludes an interesting discussion about the extent to which similarities in research and technology policy between the various nations are related to the pervasive influence of such supranational organizations as the OECD.

Throughout the book the various authors use the terms science, research, technology and innovation as though they were more or less interchangeable. This results in a lack of clarity when comparing these conceptualizations and the national experiences outlined in the book. In addition, the authors envisage a new type of more systematic policy, indicated by the term "socially oriented innovation policy." This systematic policy is described as encompassing the not yet related fragments of science, research and technology, environmental and social policy.

Unfortunately, the authors in this volume do not precisely indicate the differences between the various fragments of this new type of policy within the current policy context, which for the most part involve different actors, often having mutually conflicting interests. Any attempt to develop a new integrative policy must carefully consider the negative effects of these different interests. This raises two immediate questions: Is the new integrative perspective a sound one? Are there empirical indications that such a new perspective is actually emerging (not only in the minds of writers on science and technology policy, but also in the practice of science and technology policy)?

One problem of innovation policy is relating the activities of scientific and industrial actors in order to ensure a more innovative production. In most of the countries represented in this book (with the possible exception of Spain), this does predominantly involve a simple increase of scientific activities. It means improving the interaction between scientific and industrial actors such that new products are more rapidly developed, produced and marketed. This implies the need to develop mechanisms to improve the relationship between important societal subsystems-and not a science, research, technology or innovation policy as such. In fact, as some of the authors in this book indicate, innovation more than ever involves organizational innovation. 
This book misses the essence of the problems at hand because the authors fail to note the specific characteristics of the systems in which scientific research, technology and production currently occur; or to highlight these in their approach to the problem at hand, i.e., the development of adequate innovation policies. Accordingly, there is a large discrepancy between the conceptualizations used in the book and the nature of the problems faced by policy-makers.

This is exacerbated by the lack of cohesion between the various contributions. Some articles offer insights into the characteristics of a given country's research and technology policy experiences (Abdelmaki and Kirat on France; Kawasaki on Japan; Dalum on Denmark; Loikkanen and Seppalla on Finland; Sanz-Menendez and Munoz on Spain and Aichholzer et al. on Austria). Other articles outline social and environmental objectives and policy measures (Badham and Naschold; Udo Simonis and Latniak and Georg Simonis on Germany; Van Boxsel on The Netherlands; and Daneke on the U.S.). The former (e.g., Abdelmaki and Kirat) provide different accounts of the various countries, while the latter (e.g., Badham and Naschold) only give information in passim on the (research and technology) policy systems in the countries they are considering. More editing, and or a comparative analysis, would have been helpful here.

The authors are correct when they point out that in the past there was a distinction between policies directed towards technology development and those directed towards the control of such developments. Nevertheless, since one of the main theses of this book is that these policies should be combined in one socially oriented innovation policy, I expected to find more information about the negative effects of the separation of such policies, particularly in the empirically based articles.

Quite often, the activities in these two policy sectors (i.e., technology development and the control of such developments) are accomplished by different ministries or agencies. Generally speaking, there is little or no coordination of such policies between these agencies. In addition, the role of technology assessment as an analytic instrument to study the social effects of technologies seems to be overrated. Quite often the technology assessments that are available during the decision-making process have not had the effect intended by the proponents of this type of analysis.

This applies equally both to the current forms of technology assessment (e.g., cost/benefit analyses) and the new forms (e.g., the constructive technology assessment proposed by Van Boxsel in his contribution). In the new form, the assessment is done earlier in the developmental process of new technologies. This involves various different organizational actors relevant for the development and the implementation of the new technology. However, there are no guarantees that in this process the results of the technology assessments will actually be used, thereby combining technological and social considerations. When the technology assessment remains outside the sphere of influence of those people directly involved in developing and implementing the technology, a discrepancy persists between the development of knowledge about social 
(or environmental) issues and the development and implementation of technologies.

Generally speaking, I found that the contributors to this volume failed to pay sufficient attention to the mechanisms that should be used in the future to facilitate the coupling of social, environmental and technological concerns. One of the reasons for this is that the book focuses on the role of government rather than also considering these policies from the point of view of the other actors involved, i.e., industrial firms. In fact, technology development and innovation in most countries has predominantly been the responsibility of industrial firms. Nevertheless, in the past, all developed nations have considered the development of policies related to the stimulation and the control of research, technology and innovation to be a task for government.

However, nations differ in the role given to government with respect to the development of such policies. A comparison of the U.S. with Japan and Europe reveals that government plays a more pronounced role in Japan and Europe. In the U.S. the role of the federal government is quite substantial, albeit indirectly (especially via military contracts).

In all countries in the 1990s, there has been a tendency towards a less pronounced role for government, particularly with respect to programs designed to promote innovation. Today, the role of government is to facilitate rather than to steer or regulate. This is indicated in several places in the book in reference to various countries. Nevertheless, when redefining the role of government as being more removed from the development of research and technology policy, attention must be given to the way in which industrial firms can obtain a more substantial role in the social and environmental aspects of technology development and implementation. The authors of this book unfortunately ignore this important detail.

Even in the early 1990s, at least some industrial firms had begun to change their innovation policy. In part, this was done in order to include more flexibility, and not the development of a socially oriented innovation policy. However, such changes have consequences for their definition of work, which was the social objective of technology policy according to the authors of this book. Simultaneously, more recently many firms have paid more attention to the environmental consequences of their production processes. In part, it was done to ensure greater attention to the environmental consequences of their production processes. The latter was instigated by environmental policies-not technology policies with environmental objectives - and by the chance they saw to make money on more sound environmental production processes (e.g., in The Netherlands, Hoogovens developed processes to recycle steel; and AVEBE-also in The Netherlands-used the waste of their main production process - developing starch from potatoes-to develop semimanufactured products to be used in a variety of firms in various other industries). In both cases these new environmental objectives are central in the strategy of these firms and are directly related to $R \& D$ and technology choices of the firms involved. If these examples are not too deviant, this should also have 
consequences of the governmental policies regarding innovation and science and technology.

In this respect, it is interesting to note the discrepancy between Daneke's account of the environmental problems that resulted from the information technology development in Silicon Valley and the reaction of local, state and federal government at that time with current attempts by the EPA to make separate deals with firms to trim red tape if the latter develop adequate environmental measures. Nevertheless, the EPA only very recently closed a deal with INTEL concerning this firm's Arizona plant. It would have been valuable if the authors in this book had provided an account of the social mechanisms that promote or hamper such new developments (for example, the discussions between EPA and INTEL took a very long time). It is a pity that this book provides us with new concepts but does not pay sufficient attention to the related social mechanisms needed to implement such policiesparticularly since the relationship between governments and other relevant actors is different in the 1990s than in the preceding period.

Earlier, I raised two, mutually inclusive questions: Is the new integrative perspective a sound one? Are there empirical indications that such a new perspective is actually emerging (not only in the minds of writers on science and technology policy, but also in the practice of science and technology policy)? This book not only provides an overview of experiences with technology policy in the past, but also formulates a new perspective-particularly in the conceptual papers.

According to these authors, the requirements of the current economy and the role of technology within it warrants a completely new perspective on technology policy. They imply that this new perspective has been established in various countries in the most recent past (although not everywhere and not completely).

There is much to be said for a policy (or set of policies) that addresses related developments within science, applied science and technology and that is designed to ensure that these developments be connected in the pursuit of innovation (but this is distinct from the pursuit of social and environmental objectives). In general terms, aspects of the new perspective can be observed today in most countries in the developed world. The new perspective is most prominently formulated in the contributions of Schienstock and Badham.

In the table on page 21 in the introductory article, Schienstock outlines the general attributes of the new perspective in the context of the transition $\mathrm{R} \& \mathrm{~T}$ policy. The new approach is not specifically directed towards material technology but involves organizational and cultural aspects. It is not concerned only with economic growth but includes aspects of social and ecological compatibility. Interest is not only with the stages of fundamental research but also those stages closer to the market. The state is no longer the central actor but rather the facilitator and coordinator of a self-regulating process. The main instrument is no longer support and regulation but the provision of an infrastructure. The policy type has evolved from direct to contextual control. 
Badham sees a change from a socioeconomic to a socially oriented innovation policy. The main changes with which he is concerned are: (a) that he basis for innovation policy is no longer a rather simple technology push model; and (b) that promotion and regulation are no longer two different aspects of technology policy but are being combined in an integrative systematic kind of policy. While he particularly focuses on aspects of human resources, he perceives this integrative type of new research and technology policy as encompassing other social (and ecological) aspects as well.

An observer will recognize at least some of the aspects of new research and technology policies in different developed nations. The question is, however, whether we can conceive a new integrated policy perspective. I see no indications of the emergence of such a systematic approach to science and technology questions-to include social and environmental concerns. Some countries are further along then others; but in most countries different organizations and agencies are still responsible for different policy attributes. Nowhere has the integrated research and technology policy "arrived"-notwithstanding some token systematic organizational forms, such as interministerial councils and committees.

There is yet another concern with respect with such an integrated perspective. We have seen in the past how difficult it is to implement integrated types of policies, even where governments still have a central position in the social fabric. It is all the more difficult to implement this type of policy without government being the central actor. Within the contours of this new type of policy, Schienstock formulates a very restrained role for government. How can we guarantee the implementation of an integrated policy, considering the different interests at hand?

This reviewer underwrites the need of more adequately attuning social and environmental concerns with technological ones. I would be more interested in a rather concrete policy approach that surmounts the negative consequences of the different interests involved. Experiences such as the discussion between EPA and INTEL in the U.S. and the changes in strategy of Hoogovens and AVEBE in The Netherlands (indicated above) indicate some of the concrete ways in which firms can be convinced to attune these objectives more adequately than before.

The implementation of an integrated socially oriented innovation policy has to take place at that level: and it should therefore be formulated at that level.

In addition to the problem of the nature of the integrated policy, by all appearances the proposed new model seems more an ideal than an indication of empirical developments in the field. It is interesting to make an overview of the empirical evidence-provided in this book-for the integrated policy approach by considering the experiences of the various countries.

Earlier, I indicated that the book does not facilitate a systematic comparison of policies in the various countries, notwithstanding that at least two of the articles on the German experience focus on aspects of the humanization of work and technology. The article by Edquist includes em- 
pirical information about Sweden but deals with the role of the Swedish Technology Board and not the Work Environment Fund, which would have been interesting to compare with the German experiences.

I read the empirical articles to determine the extent to which an integrated perspective was reported in any one of the countries. When comparing the articles from this point of view, it is surprising that some of them deal with the increasing focus on environmental concerns in technology policy (the contributions by Daneke; Simonis; Abdelmalki and Kirat); while others focus on social concerns--here to be read as attention to aspects of the humanization of work rather than more general social concerns (the contributions of Badham; Badham and Naschold; Latniak and Simonis). All of these articles deal with specific programs directed towards the development of environmental or work objectives in light of technology, cum innovation policy.

More confusing was the fact that in other contributions the social (and environmental) concerns were conceptualized in a more generic way, i.e., indicating that it would be necessary in technology and innovation policy to take into account that the conditions and consequences of such policies would have ramifications in other subsystems in society (the contributions of, for example, Edquist, Dalum, Loikkanen and Seppala, and Aichholzer).

Considering these empirical accounts of attempts in various European countries to involve social and ecological concerns in technology and innovation policies, it is safe to conclude that, to a growing extent in recent decades, these concerns have been taken care of in European countries. But to consider this as an emerging integrative perspective goes too far. Actually, in a number of the articles the various objectives that have to be integrated are treated in terms of "dilemmas" and "paradoxes." Apparently, the new conceptualization with which the book opens has to be understood as an "ideal."

This brings me to a theme that is especially appropriate to discuss in the present journal. Most of the authors in this volume discuss policies in their respective countries, and in one capacity or another they have been directly involved in the development, implementation and/or evaluation of these policies. This raises the questions: To what extent do their comments about the various national experiences represent an analysis of their own experiences? Or are they simply self-reflective comments about their successful (or not so successful) attempts to influence policymaking? To what extent is their new model of integrated social and environmental technology policy a new attempt to influence policy-making? For example, over the years, the Berlin Wissenschaftszentrum has paid ample attention to the process of work humanization. It is not a coincidence that in Germany, more than in other European countries (with the possible exception of Sweden), special attention has been paid to the consequences of technology implementation for aspects of the humanization of work. Of course, this is not only a result of the activities of the Berlin Wissenschaftszentrum; it is also, in both Germany and Sweden, related to the pronounced role of the labor unions. At least in part, the develop- 
ment of such programs reflects the successful interventions of social scientists developing new policy concepts.

I would like to refer to a remark in one of the articles on Germany (Latniak and Simonis) that the "Mensch und Technik" program of North RhineWestphalia involved the work of some three hundred social and technical scientists for a shorter or longer period. It is significant that the "integrated policy concept" is not based on integrated research. Rather, as the various articles (and other research by the authors) indicate, it is based upon research in quite diverse fields of social and technical scientific research.

In this respect, too, we still have a far way to go before the integrated socioecological perspective on innovation policy becomes fact.

\section{Note}

1. Unfortunately, these countries do not receive equal and comparable attention. For example, the article concerned with The Netherlands focuses on one specific aspect of technology policy: technology assessment, the article on the U.S. is confined to a discussion of the environmental effects of new technological developments concentrated in such small geographic areas as Silicon Valley.

The main argument in the book is that this field of policy has experienced various reorientations in the past, and currently needs a major new perspective. This new perspective is identified as an integrative systems approach including the social and environmental consequences of technology development. This is in contrast to a consideration of technology policy as a question of promoting the development of technology and its subsequent control. 